\title{
The many faces of idiopathic oedema of women
}

\author{
JOHN FEELY \\ B.Sc., M.R.C.P.I., M.D. \\ Department of Pharmacology and Therapeutics, University of Dundee, Ninewells Hospital and \\ Medical School, Dundee, DD1 9SY
}

\begin{abstract}
Summary
The variable presentation and paucity of physical signs in idiopathic oedema may commonly delay diagnosis. The resultant unnecessary investigations and hazardous treatment are described for six patients. The management of these patients is discussed in the light of the current controversy concerning the role of diuretics in the pathophysiology of this condition.
\end{abstract}

\section{Introduction}

Although the clinical entity of idiopathic oedema or periodic swelling in young women has been described for many years (Thorn, 1957) the episodic nature of physical signs and unfamiliarity with its variable presentation may frequently delay diagnosis. This, together with a lack of sustained clinical response to diuretics, the apparent but inappropriate symptomatic therapy, has caused considerable resentment and frustration to patient and doctor alike (Leading Article, 1976). This report draws attention to the unnecessary investigations and potentially hazardous treatment that may result from its variable presentation.

\section{Case histories}

The six patients were seen at an out-patient department. All had initially presented to various specialities (Table 1) and had undergone extensive investigation for some years (mean 5 years) before the diagnosis of periodic oedema was made. This was based on objective evidence of a diurnal weight variation in excess of $1.4 \mathrm{~kg}$ and the exclusion of cardiac, renal, hypoproteinaemic or hepatic disease by clinical examination, blood urea and electrolytes, liver function tests, electrocardiogram and chest $\mathrm{X}$-ray. All medication, including diuretics, was withdrawn.

Case 1

Symptoms began in 1971 when the patient noted swelling and 'puffiness' of the face subsiding by midday by which time the abdomen and breasts were 'bloated'. By evening, pitting oedema of the

TABLE 1. Speciality referrals, investigations and treatment before diagnosis

\begin{tabular}{|c|c|c|c|}
\hline Case no. & $\begin{array}{c}\text { Age (in years) at onset (and } \\
\text { years to diagnosis) }\end{array}$ & Speciality referrals & Procedures (notable features) \\
\hline 1 & $37(5)$ & $\begin{array}{l}\text { Gynaecology } \\
\text { Urology } \\
\text { Endocrinology } \\
\text { General medicine }\end{array}$ & $\begin{array}{l}\text { Hysterectomy } \\
\text { IVP and cystoscopy } \\
\text { (Diuretic abuse, hypokalaemia) }\end{array}$ \\
\hline 2 & $41(9)$ & $\begin{array}{l}\text { Gynaecology } \\
\text { Endocrinology } \\
\text { Urology } \\
\text { Neurosurgery }\end{array}$ & $\begin{array}{l}\text { IVP } \\
\text { Brain scan }\end{array}$ \\
\hline 3 & $51(2)$ & $\begin{array}{l}\text { Gastroenterology } \\
\text { Endocrinology }\end{array}$ & $\begin{array}{l}\text { Investigated for ascites } \\
\text { Rings removed from fingers } \\
\text { (Subclinical hypothyroidism) }\end{array}$ \\
\hline 4 & $34(1)$ & $\begin{array}{l}\text { Gynaecology } \\
\text { General medicine }\end{array}$ & $\begin{array}{l}\text { Laparoscopy } \\
\text { (Anxiety) }\end{array}$ \\
\hline 5 & $40(2)$ & $\begin{array}{l}\text { Cardiology } \\
\text { General medicine }\end{array}$ & $\begin{array}{l}\text { Diuretic induced oedema } \\
\text { (Anxiety) }\end{array}$ \\
\hline 6 & $30(10)$ & $\begin{array}{l}\text { Endocrinology } \\
\text { Gynaecology } \\
\text { Psychiatry }\end{array}$ & $\begin{array}{l}\text { Obesity } \\
\text { (Diet-induced attacks) }\end{array}$ \\
\hline
\end{tabular}


ankles was present. Episodes lasted 3-4 days, remitting spontaneously only to recur 2-3 times each month, particularly premenstrually. Some 6 months later, following an episode of abdominal pain attributed to salpingitis and repeated attacks of abdominal swelling, hysterectomy was performed for 'chronic pelvic inflammation'. Histology was normal. Periodic swelling persisted and over the subsequent three years the patient had urological and extensive and repeated biochemical and endocrinological (adrenal, pituitary, ovarian and thyroid function tests) investigations for the symptoms of oliguria during, and polyuria after the attacks of oedema.

When she presented again in 1977 the patient had acquired two complete outfits of clothing commonly returning home at midday to change before continuing work. She had thiazide diuretics initially and subsequently frusemide (up to 120 $\mathrm{mg}$ /day without potassium supplements). She was also overweight, and there was objective evidence of a marked variation in bust $(9 \mathrm{~cm})$, waist $(10 \mathrm{~cm})$ and weight $(3 \mathrm{~kg})$ measurements during attacks (Fig. 1). She abused frusemide and at the time of presentation complained of lethargy which was probably attributable to hypokalaemia $(2.5 \mathrm{mmol} / \mathrm{l})$. Having had numerous attacks while off all therapy and a continuous low-calorie low-salt diet for one year the patient now is content to rely on the occasional use of a combination of a thiazide and amiloride for an attack which coincides with an important social or psychological event. The greatest therapeutic benefit to the patient has come from her understanding and that of her family (who also suffered at the time of attacks) of the basis and benign nature of this condition.

\section{Case 2}

This woman was initially referred to hospital in 1969 because of premenstrual tension and intramenstrual facial and ankle swelling. Gynaecological assessment was normal. During the subsequent six years she was repeatedly referred to and from gynaecologist to endocrinologist to urologist without any apparent abnormality being detected. Neurosurgical investigation for a migrainous type headache during the attacks was also normal. Following diagnosis, the patient was able, with considerable difficulty, to discontinue both diuretics and analgesics that she had been prescribed for symptomatic relief and, during the last year off all medication, has suffered only two attacks compared to $10-15$ in the previous years.

\section{Case 3}

Initially this woman attributed her marked intermittent abdominal and ankle swelling to the menopause. During one episode of hand oedema her rings were removed by cutting at a casualty department and, because of marked abdominal swelling, she was referred to a gastroenterologist for in vestigation of ascites. Subsequently she was found to have subclinical hypothyroidism and responde favourably to thyroxine, without any recurrence of periodic swelling.

\section{Case 4}

On her second attack of mild facial and marked

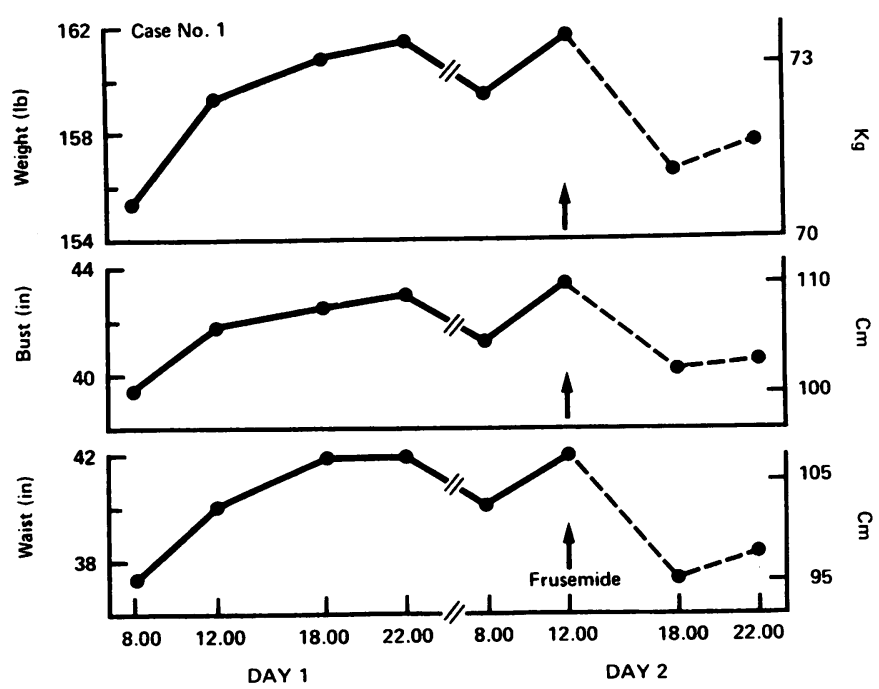

FIG. 1. Typical measurements during an attack of idiopathic oedema showing diurnal weight gain and the effect of diuretics. 
abdominal oedema this patient was admitted as a a gynaecological emergency and underwent a negative laparoscopy for a possible ovarian cyst. Subsequently she was referred to a medical clinic with anxiety about her general health. Episodes of periodic swelling unrelated to the menstrual cycle continue to recur two to three times per year and are managed by bed rest alone.

\section{Case 5}

Although investigations of marked ankle oedema during warm weather at two clinics were normal, thiazide diuretics were prescribed. The patient was subsequently given frusemide and the episodes of ankle oedema were then accompanied by a bloated sensation in the breasts and abdomen. This apparent worsening convinced the patient that she had intractable heart disease. Withdrawal of diuretics has been associated with the disappearance of breast and abdominal swellings. Off all therapy, the patient continues to have ankle oedema and anxiety concerning her health.

\section{Case 6}

Periodic oedema particularly associated with a relaxation of dietary restrictions for obesity was repeatedly investigated over a 10 -year period. The patient discontinued diuretic therapy which was repeatedly prescribed. Because of a lack of physical signs despite considerable complaints the patient underwent a normal psychiatric evaluation. Following diagnosis, attempts at a sustained low calorie diet have been unsuccessful and periodic oedema continues.

\section{Discussion}

Although the general acceptance of easily measured diagnostic criteria (diurnal weight gain in excess of $1.4 \mathrm{~kg}$ in the absence of secondary causesThorn, 1968; Edwards and Bayliss, 1975) has facilitated recognition of this common condition, cases are frequently undiagnosed for many years. Symptoms such as puffiness of the face, a bloated sensation and marked swelling of breasts, abdomen and ankle may vanish as soon as the patient is investigated at rest in hospital. The nature of these and the attendant non-specific symptoms such as fatigue and headache commonly lead to unnecessary investigation and an erroneous label of anxiety. Typically, the condition occurs in females between 20-45 years of age and may at first appear to be an exaggeration of premenstrual symptoms. During the course of the day oedema tends to move from the face and hands to the breasts and abdomen associated with standing, and by late afternoon or evening is most marked at the ankles. The excess weight gain is not, as occurs in normal subjects, lost by the following day and subjects begin the next day heavier. This stepwise increase in weight occurs for some days until there is a spontaneous or, more commonly (Fig. 1), diuretic-induced diuresis. Patients frequently graduate from thiazides to the more potent loop diuretics which they commonly abuse, and hypokalaemia as in Case 1 is not uncommon. In the cases described in this report the apparent accumulation of fluid in one particular part of the body or attention to one symptom in particular lead to a diversity of specialist referrals and investigations (Table 1). In addition, patients have also presented with cerebral or pulmonary oedema (Edwards and Bayliss, 1975). However, in those patients who were considered to have ascites, ovarian cysts, cardiac or renal disease, there was evidence of a diurnal weight gain, and once considered the condition rarely requires detailed investigation. The failure to recognize idiopathic oedema may also be attributed to the omission of this common condition from consideration in the majority of standard text books. The recent recognition that subclinical hypothyroidism, as in case 3 , may present as idiopathic oedema (Al-Khader and Aber, 1979) suggests that thyroid function should also be included in the exclusion criteria for diagnosis.

The cause of this condition remains obscure. Central to the development of a typical attack appears to be marked hypovolaemia upon assumption of the erect posture which is associated with exaggeration of the normal compensatory responses, inappropriate proximal renal tubular reabsorption of sodium, activation of the renin-angiotensin system, secondary aldosteronism and ADH secretion (Streeten et al., 1973; Edwards and Bayliss, 1975). In the upright position, these patients have a delay in the excretion of a water load and an inability to dilute urine (Zech, Pozet and Carreras-Berges, 1977). Based on uncontrolled ${ }^{125}$ I-labelled albumin studies (Edwards and Bayliss, 1975), it has been suggested that an abnormally large leak of plasma fluid from the circulation leads to a profound fall in plasma volume.

Recently, MacGregor et al. (1979) argued that the majority if not all cases are due initially to diuretics or a sudden increase in sodium and carbohydrate intake following periods of marked self-imposed starvation. Diuretic-induced hypovolaemia and stimulation of the renin-angiotensin-aldosterone system leads to salt and fluid retention. They demonstrated that, following an initial period of weight gain, diuretic withdrawal or a low salt diet lead to a permanent remission in the majority of patients. While undoubtedly in many patients (e.g. Cases $1,2,5,6$ ) diuretics or dietary manipulation may cause or propagate the condition, there 
are many other cases where these factors cannot be implicated (Edwards and Dent, 1979; Lagrue, Behar and Baillet, 1979). It is perhaps the latter patients who do not, as suggested by MacGregor et al. (1979), almost invariably respond to withdrawal of diuretics. Certainly, some of the patients described both here and by Edwards and Dent (1979) continued to have attacks one year following withdrawal of diuretics. The use of a longer acting thiazide with an aldosterone antagonist (reducing the risk of hypokalaemia and secondary hyperaldosteronism) reduces the severity of attacks in these patients. Case reports describing the successful use of dopaminergic agonists (Norbiato et al., 1979) or captopril (Mimran and Targhetta, 1979) should at present be viewed as experimental methods of decreasing the contributory role of the reninangiotensin system. Because of the episodic nature of the condition it is essential that properly controlled clinical trials be carried out to establish the therapeutic merits of any treatment. Until this happens, and having dealt with diuretic or dietary induced attacks, patients are best managed in a supportive manner.

\section{References}

Al-Khader, A.A. \& Aber, G.M. (1979) The relationship between the idiopathic oedema syndrome and subclinical hypothyroidism. Clinical Endocrinology, 10, 271.

EDWARDS, O.M. \& BAYLISS, R.I.S. (1975) Idiopathic oedema of women: a clinical and investigative study. Quarterly Journal of Medicine (new series), 45, 125.

EDWARDS, O.M. \& DENT, R.G. (1979) Idiopathic oedema. Lancet, i, 1188.

Lagrue, G., Behar, A. \& Baillet, J. (1979) Idiopathic oedema. Lancet, i, 1188.

LEADING ARTICLE (1976) Idiopathic oedema of women British Medical Journal, 1, 979.

MacGregor, G.A., Markandu, N.D., Roulston, J.E., JoNES, J.C. \& DE WARDENER, H.E. (1979) Is idiopathic oedema idiopathic? Lancet, i, 397.

Mimran, A. \& Targhetta, R. (1979) Captopril treatment of idiopathic oedema. New England Journal of Medicine, 301, 1289.

Norbiato, G., Bevilacqua, M., Raggi, U., Micossi, P., Nitti, F., Lanfredini, M. \& Barbieri, S. (1979) Effect of metoclopramide, a dopaminergic inhibitor on renin and aldosterone in idiopathic edema: Possible therapeutic approach with levodopa and carbidopa. Journal of Clinical Endocrinology and Metabolism, 48, 37.

Streeten, D.H.P., Dalakos, T.G., Souma, M. Fellerman, ì H., Clift, G.V., Schletter, F.E., Stevenson, C.T. \& SPELler, P.J. (1973) Studies of the pathogenesis of idiopathic oedema. The roles of postural changes in plasma volume, plasma renin activity, aldosterone secretion rate and glomerular filtration rate in the retention of sodium and water. Clinical Science and Molecular Medicine, 45, 347.

Thorn, G.W. (1957) Cyclical edema. American Journal of Medicine, 23, 507.

THORN, G.W. (1968) Approach to the patient with idiopathic edema or periodic swelling. Journal of the American

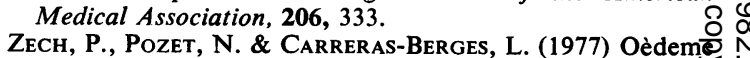
cyclique idiopathique: trouble de l'élimination hydrique à majoration orthostatique. La Nouvelle Presse Médicale, 1121. 